\title{
CTD small phosphatase like 2 (CTDSPL2) can increase $\varepsilon$ - and $\gamma$-globin gene expression in K562 cells and CD34+ cells derived from umbilical cord blood
}

\author{
Yan-Ni Ma, Xin Zhang, Hai-Chuan Yu, Jun-Wu Zhang*
}

\begin{abstract}
Background: A potential strategy for treatment of sickle cell disease (SCD) and $\beta$-thalassemia in adults is reactivation of the $\varepsilon^{-}$and $\gamma$-globin genes in the adult. We aimed to identify trans-activators of $\varepsilon^{-}$and $\gamma$-globin expression and provide new candidate targets for effective treatment of sickle cell disease (SCD) and $\beta$-thalassemia through activation of $\varepsilon^{-}$and $\gamma$-globin genes in adults.

Results: We identified a CTD small phosphatase like 2 (CTDSPL2) gene that had higher transcription levels in umbilical cord blood (UCB) than in adult bone marrow (BM). Also, transcription of the CTDSPL2 gene increased significantly during erythroid differentiation. Further, we found that overexpression of CTDSPL2 could obviously improve the expression of $\varepsilon^{-}$and $\gamma$-globin genes in K562 cells. Meanwhile, the repression of CTDSPL2 by RNA interference decreased expression of $\varepsilon$ - and $\gamma$-globin genes but did not inhibit the increase of globin gene expression during K562 erythroid differentiation. In addition, the enforced expression of CTDSPL2 gene mediated by lentiviruses could also increase $\boldsymbol{\varepsilon}^{-}$and $\gamma$-globin gene expression during erythroid differentiation of CD34+ cells derived from UCB.
\end{abstract}

Conclusion: CTDSPL2 gene can obviously improve the expression of $\varepsilon^{-}$and $\gamma$-globin genes in K562 cells and CD34+ cells derived from UCB. Our study provides a new candidate target for effective treatment of SCD and $\beta$-thalassemia.

\section{Background}

During development the expression of human $\beta$-like globin genes displays two switches: the embryonic ( $\varepsilon$-) to fetal ( $\mathrm{G} \gamma$ - and $\mathrm{A} \gamma$-) globin switch, coinciding with the transition from embryonic (yolk sac) to definitive (fetal liver) haematopoiesis, and the fetal to adult ( $\beta$-) globin switch, occurring near the parturient period with the establishment of bone marrow as the main site of hematopoiesis [1,2]. It has been shown that fetal hemoglobin ( $\left.\mathrm{HbF}, \alpha_{2} \gamma_{2}\right)$ expression can be reactivated during adult erythropoiesis [3]. The increased production of fetal hemoglobin could ameliorate the clinical severity of sickle cell anemia (SCD) and $\beta$-thalassemia [3]. Therefore, attempts are underway to

\footnotetext{
* Correspondence: junwu_zhang@pumc.edu.cn National Laboratory of Medical Molecular Biology, Institute of Basic Medical Sciences, Chinese Academy of Medical Sciences and Peking Union Medical College, 5 Dong Dan San Tiao, Beijing 100005, People's Republic of China
}

screen for pharmaceuticals that reactivate $\gamma$-globin production in adults. Hydroxyurea and sodium butyrate derivatives have been already been examined and used for treatment of $\beta$-hemoglobinopathies [4-8]. While these therapies are effective for treating SCD and $\beta$-thalassemia, they also have adverse effects such as suppression of cell growth and bad effects in long-term treatment $[9,10]$.

An alternative treatment strategy is to increase $\gamma$-globin expression by controlling potential transcription factors that specifically activate $\gamma$-globin expression in the fetus or result in $\gamma$-globin gene silencing in the adult. To identify genes encoding such factors, we analyzed differential expression of mRNA in erythroid induction cultures of CD34+ hematopoietic progenitor cells derived from normal adult bone marrow (BM) and umbilical cord blood (UCB). One of the differentially expressed genes was further examined for effects on globin gene expression. 
Expression levels of the CTD small phosphatase like 2 (CTDSPL2) gene were higher in UCB than in healthy adult BM. CTD phosphatase dephosphorylates the CTD tail of the largest subnit of RNA polymerase II (RNAPII). In vivo, the C-terminal domain (CTD) of the largest subunit of RNA polymerase II is either phosphorylated or dephosphorylated. Dynamic, site-specific phosphorylation/ dephosphorylation of the CTD occurs during the transcription cycle [11]. Recent observations indicate that CTD phosphorylation plays a major role in orchestrating interaction of the CTD with mRNA processing factors involved in capping, splicing and polyadenylation. Several kinases modify the CTD phosphorylation state. However, only a few mammalian CTD phosphatases have been identified. FCP1, the first characterized CTD phosphatase, contains a BRCT domain required for RNAPII interaction and CTD dephosphorylation [12]. SCP1 and UBLCP1 contain phosphatase domains similar to FCP1, and also dephosphorylate Ser-2 and Ser-5 of phosphorylated CTD in vitro [13]. The CTDSPL2 gene product contains a CTD phosphatase catalytic domain (CPDc) and the gene is $47 \%$ homologous to FCP1. The function of this gene is not known although it has been shown to dephosphorylate phophoserine-5 and phosphoserine-2 within GST-CTDo in vitro [14].

In this study, we show that overexpression of CTDSPL2 significantly increased the $\varepsilon$ - and $\gamma$-globin gene expression in $\mathrm{K} 562$ cells and CD34+ cells derived from UCB while have faint effect on $\zeta_{-}, \alpha$ - and $\beta$-globin gene.

\section{Results}

\section{Expression pattern of CTDSPL2 in BM and UCB and} during erythroid differentiation

We analyzed differential expression of genes in CD34+ erythroid induction cell cultures derived from normal adult BM and UCB by differential display reverse transcription PCR (DDRT-PCR). CTDSPL2 had higher expression levels in erythroid cultures derived from UCB than from healthy adult BM. Differential expression of CTDSPL2 was also detected by real-time PCR. Expression levels of CTDSPL2 mRNA in UCB erythroid cultures were 2.6 times greater than in healthy adult BM erythroid cultures (Fig. 1A).

The level of CTDSPL2 mRNA during Epo-induced erythroid differentiation in UCB-derived CD34+ HPCs was measured by real-time PCR. CTDSPL2 mRNA levels increased during erythroid differentiation (Fig. 1B). The mRNA expression of CTDSPL2 in hemin- and butyrateinduced K562 cells was measured by Northern blot analysis (Fig. 1C). CTDSPL2 mRNA levels were also measured by real-time PCR at different time points during hemininduction of K562 cells (Fig. 1D). Levels of CTDSPL2 mRNA increased in hemin- and butyrate-induced $\mathrm{K} 562$ cells. CTDSPL2's increase was more evident during hemin-induced $\mathrm{K} 562$ cell differentiation.

\section{Overexpression of CTDSPL2 increases hemoglobin-} containing cells during erythroid differentiation of K562 cells We collected five stable pools of K562 cells transfected with pc3.1-CTDSPL2 (each pool was originally from a collection of 20 to 30 individual clones). Real-time PCR analysis revealed that transcription of the CTDSPL2 gene in these five transfectant pools was on average 2 times greater than in the $\mathrm{K} 562 / \mathrm{pc} 3.1$ transfectant pools and in un-transfected $\mathrm{K} 562$ cells (Fig. 2A). The Western blot analysis also revealed an obvious increase of CTDSPL2 protein in the K562/pc3.1-CTDSPL2 transfectant pools (Fig. 2B).

Erythroid differentiation was induced in stable $\mathrm{K} 562$ transfectants and un-transfected $\mathrm{K} 562$ cells by hemin. The cells were collected and analyzed by benzidine staining $0,12,24,36,48,60,72 \mathrm{~h}$ after hemin induction (Fig. 2C). Among the five pc3.1-CTDSPL2 transfectant pools, there were four (A, C, D and E) with especially high benzidine-positive cell levels. Before erythroid differentiation, $17-22 \%$ of the cells were benzidine-positive, which is equivalent to that in control cells $60 \mathrm{~h}$ after being induced by hemin. For these four transfectant pools, benzidine-positive cells were $75-80 \%$ at $72 \mathrm{~h}$ after hemin induction, significantly greater than for control cells. The percentage of benzidine-positive cells in the transfectant pool B was also higher than control cells during erythroid differentiation.

\section{Overexpression of CTDSPL2 increases $\varepsilon$ - and $\gamma$ - globin gene expression in $\mathrm{K} 562$ cells}

The transcription of a number of globin genes (including $\alpha_{-}, \zeta_{-}, \varepsilon_{-}^{-}, \gamma-$ and $\beta$-globin genes) was analyzed by real-time PCR in the K562 transfectants. Overexpression of the CTDSPL2 gene significantly increased transcription of $\varepsilon$ - and $\gamma$-globin genes in $K 562$ cells but had little effect on $\alpha-, \zeta$ - and $\beta$-globin gene transcription. Transcription of $\varepsilon$ - and $\gamma$-globin genes in the stable K562 pc3.1-CTDSPL2 transfectant pools was 12 and 6 times greater respectively than $\mathrm{K} 562 / \mathrm{pc} 3.1$ transfectant pools and untransfected K562 cells (Fig. 2D). The improvement on $\alpha-, \zeta$ - and $\beta$-globin gene expression was weak relative to the effects on $\varepsilon$ - and $\gamma$-globin genes.

Erythroid differentiation in the transfected cells was induced by hemin. Cells were collected $72 \mathrm{~h}$ after hemin induction. Overexpression of CTDSPL2 increased expression of $\varepsilon$ - and $\gamma$-globin genes after erythroid differentiation of K562 cells (Fig. 2E). The expression of $\varepsilon$ - and $\gamma$-globin gene was 7 and 3.5 times greater respectively in the K562 transfectants overexpressing CTDSPL2 than in K562/pc3.1 control cells and K562 

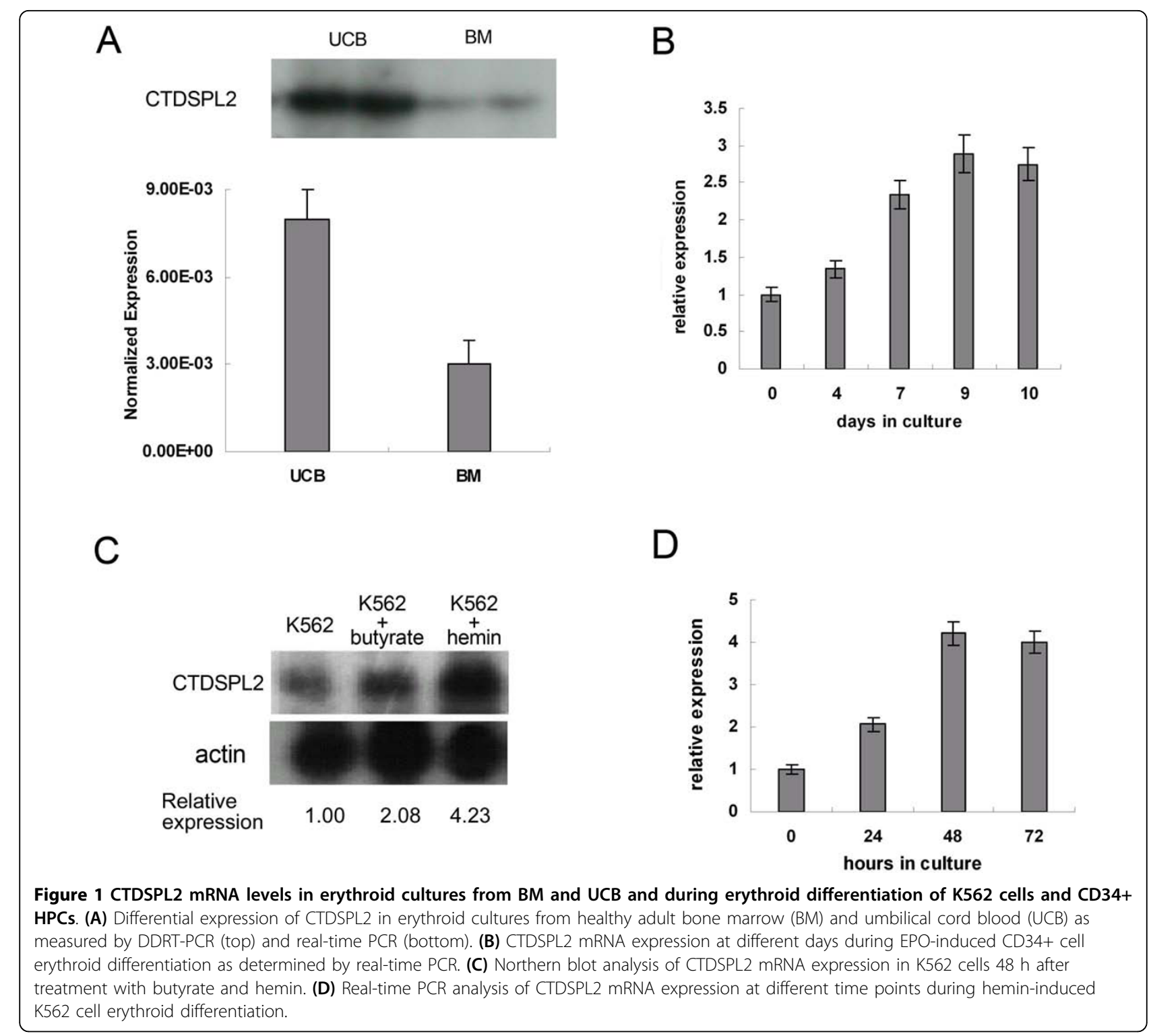

cells after erythroid differentiation. The effects of CTDSPL2 overexpression on globin gene transcription were less before erythroid differentiation than after differentiation.

Transcription of $\alpha-, \varepsilon-, \gamma$ - and $\beta$-globin genes in the transfected K562 cells before and after erythroid differentiation was also analyzed by RNase protective assay. Before hemin induction (Fig. 3A), $\varepsilon$-globin mRNA levels in the stable K562/pc3.1-CTDSPL2 transfectants were significantly higher than in control cells. $\gamma$-globin mRNA levels in K562/pc3.1-CTDSPL2 transfectants were also greater relative to control cells which have high $\gamma$-globin mRNA levels. $\alpha$-globin mRNA in K562/pc3.1-CTDSPL2 transfectants was greater than in control cells but $\alpha$-globin mRNA was still at a low level. $\beta$-globin mRNA was undetected in all samples.
After hemin induction, transcription of all globin genes excluding $\beta$-globin increased in all cells (Fig. 3B). Levels of $\varepsilon$ - and $\gamma$-globin mRNA in the stable K562/ pc3.1-CTDSPL2 transfectants was higher than in control cells. Transcription of the $\alpha$-globin gene in the stable K562/pc3.1-CTDSPL2 transfectants was also higher than in the control cells but the $\alpha$-globin mRNA was still at a low level. $\beta$-globin mRNA was still undetected after erythroid differentiation.

\section{Repression of CTDSPL2 gene decreases the number of hemoglobin-containing $\mathrm{K} 562$ cells}

Recombinant RNAi plasmids (RNAiA, RNAiB) and the pSilencer2.1-U6-Neo control vector were co-transfected into Hela cells with the CTDSPL2-GFP fusion expression plasmid. CTDSPL2-GFP expression was observed to 
A

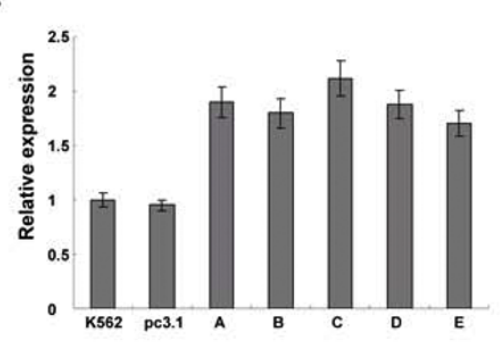

D
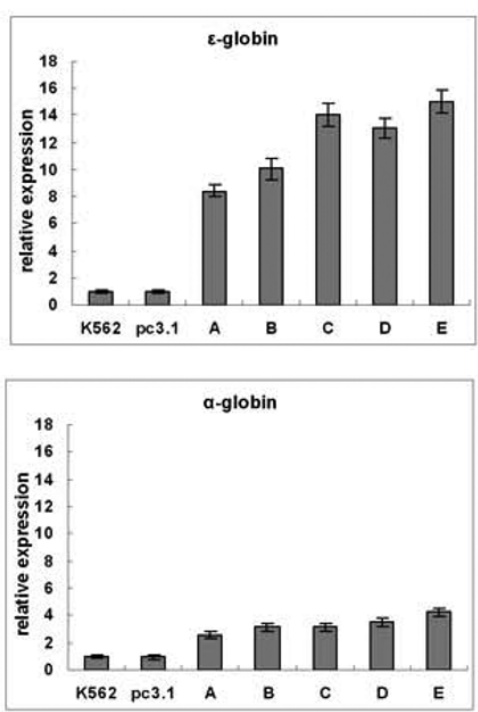

E
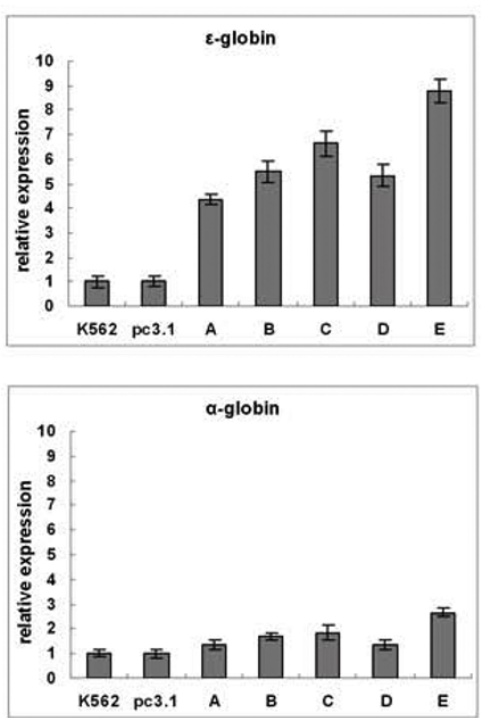

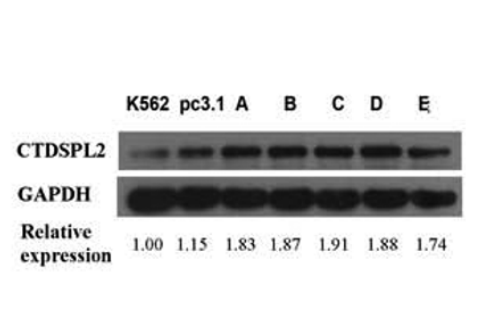

C

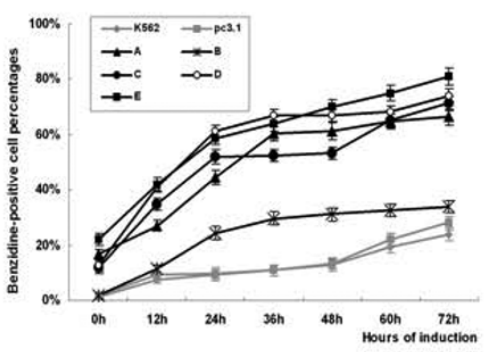

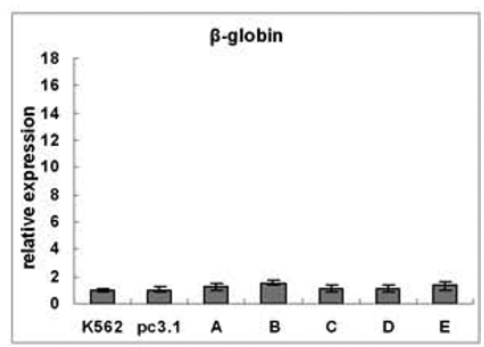
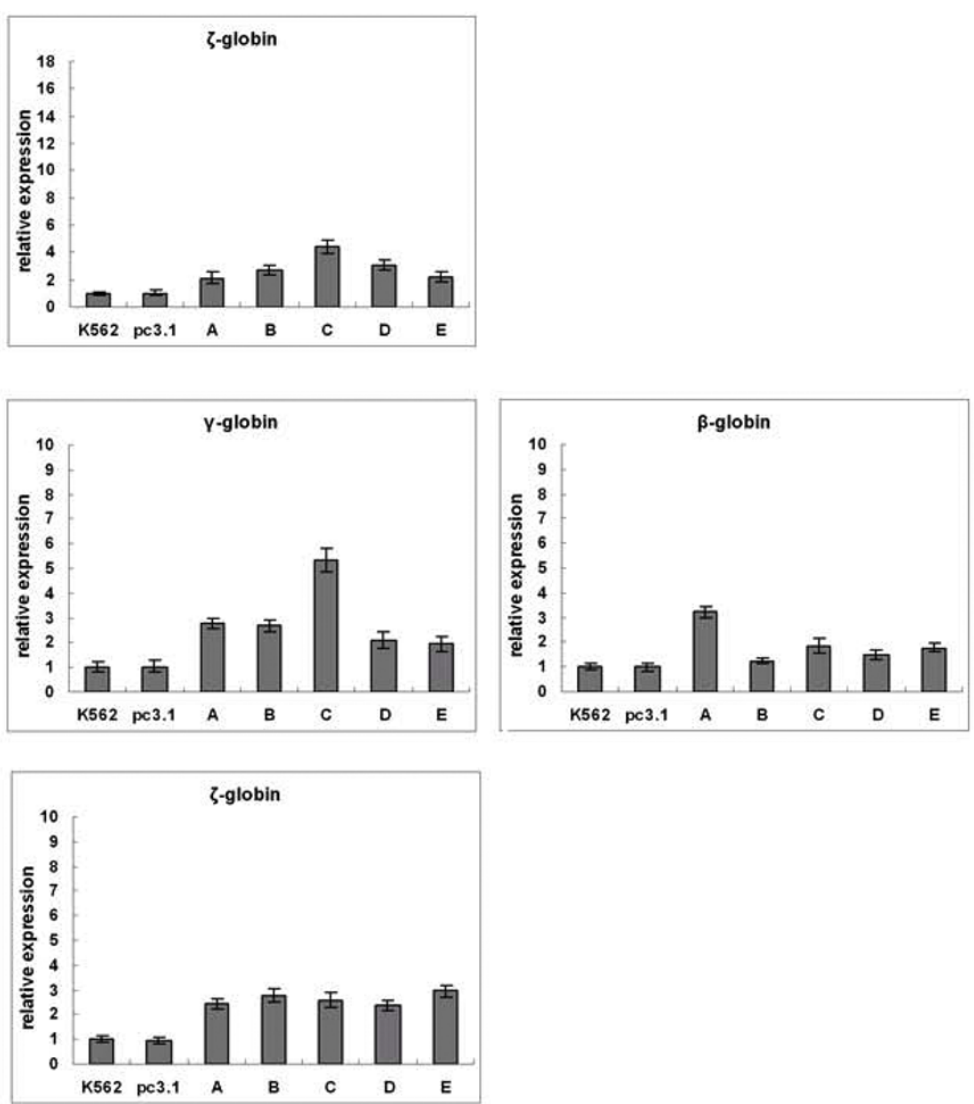

Figure 2 Overexpression of CTDSPL2 increases $\boldsymbol{\varepsilon}$ - and $\boldsymbol{\gamma}$ - globin gene expression in K562 cells. (A) Overexpression of CTDSPL2 mRNA in stable K562/pc3.1-CTDSPL2 transfectant pools as analyzed by real-time PCR. (B) Overexpression of CTDSPL2 protein in stable K562/pc3.1-

CTDSPL2 transfectant pools as analyzed by Western blot. (C) Hemoglobin-containing cells were detected by benzidine staining during hemininduced erythroid differentiation of K562 cells. The data were obtained from three independent experiments and the error bars represent standard deviation. (D) Real-time PCR analysis of $\alpha-, \zeta_{-}, \varepsilon_{-}^{-}, \boldsymbol{\gamma}$ - and $\beta$-globin genes mRNA expression in K562 cells, K562/pc3.1 transfectants and K562/pc3.1-CTDSPL2 transfectants. (E) Real-time PCR analysis of $\alpha-, \zeta_{-}, \varepsilon^{-}, \boldsymbol{\gamma}$ - and $\beta$-globin mRNA expression in K562 cells, stable K562/pc3.1 transfectants and K562/pc3.1-CTDSPL2 transfectants $72 \mathrm{~h}$ after treatment with hemin. K562 and pc3.1 represent K562 cells and stable K562/pc3.1 transfectant pool respectively. A, B, C, D and E represent the five stable K562/pc3.1-CTDSPL2 transfectant pools respectively. 


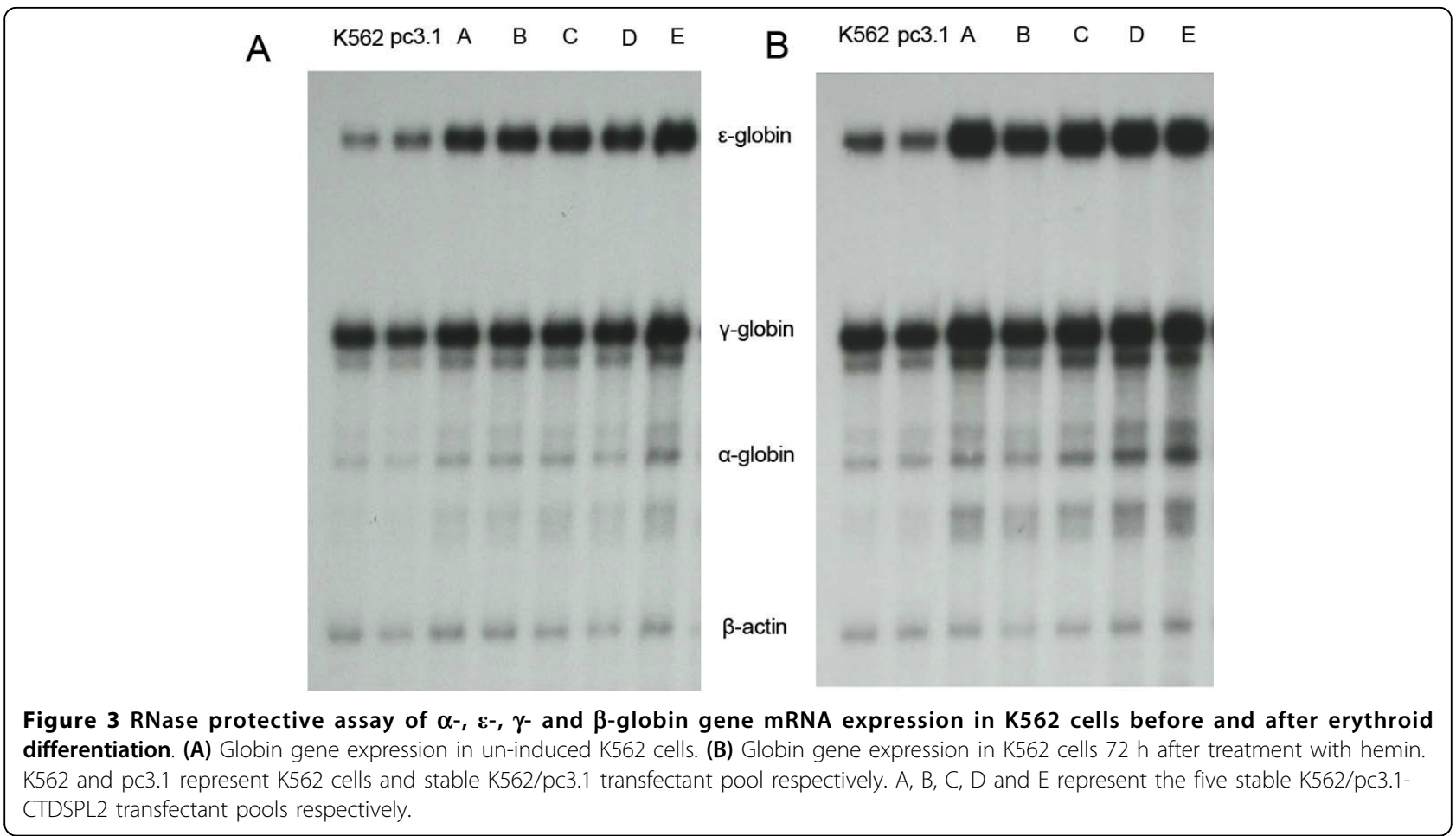

confirm CTDSPL2 repression in the cells. Expression of CTDSPL2-GFP was strongly repressed in Hela cells transfected with RNAiA and RNAiB compared to cells transfected with pSilencer2.1-U6-Neo (Fig. 4A). Both the intensity of green fluorescence in each cell and the number of cells that express green fluorescent protein decreased. RNAiB transfection resulted in greater repression of fluorescence. These results indicate that these two RNAi plasmids repress expression of CTDSPL2-GFP effectively. As the repression efficiency of RNAiB was much greater, RNAiB (1057 AAGGTGTATGCAGACAAGTTA) was used in further experiments.

RNAiB was subcloned into the PLVTHM vector and high titer lentiviruses were acquired. By lentivirus infection, we got stable K562/CTDSPL2RNAi transfectant pool. CTDSPL2 mRNA level measured by real-time PCR in the stable K562/CTDSPL2 RNAi transfectant pool was $40 \%$ of that in the control cells (Fig. 4B). An increased CTDSPL2 mRNA level in the stable K562/ CTDSPL2 RNAi transfectant pool was detected after hemin induction $72 \mathrm{~h}$ but it was only $55 \%$ of that in the hemin-induced control cells.

Erythroid differentiation was induced in stable K562/ CTDSPL2 RNAi transfectant pool and control cells by hemin and the cells were collected and analyzed by benzidine staining at different time points after hemin induction (Fig. 4C). Benzidine-positive cell percentages in stable K562/CTDSPL2 RNAi transfectant pool were lower than in control cells at the early erythroid differentiation stage.
However, this phenomenon disappeared after hemin induction $48 \mathrm{~h}$. The phenomena suggested that the repression of CTDSPL2 gene in K562 cells could decrease the hemoglobin-containing cells but could not inhibit the increase of hemoglobin-containing cells during hemininduced K562 cells erythroid differentiation.

\section{Repression of CTDSPL2 gene in K562 cells can decrease the expression of $\varepsilon$ - and $\gamma$-globin gene}

The transcription of $\alpha-, \zeta_{-}, \varepsilon_{-}, \gamma-$ and $\beta$-globin genes in the stable K562/CTDSPL2 RNAi transfectants and control cells were analyzed by real-time PCR before and after erythroid differentiation. Before hemin induction, $\varepsilon$ - and $\gamma$-globin transcription in the K562/CTDSPL2 RNAi transfectants was much less than that in control cells (Fig. 4D). $\varepsilon$-globin gene transcription was only $25 \%$ of that in control cells while $\gamma$-globin transcription was $41 \%$ of that in control cells. $\beta-, \zeta$ - and $\beta$-globin gene transcription was also less than that in control cells but the difference was not significant. $72 \mathrm{~h}$ after hemin induction, no significant difference of any globin gene transcription was found between the stable K562/ CTDSPL2 RNAi transfectants and control cells (Fig. 4E).

CTDSPL2 overexpression increases $\varepsilon$ - and $\gamma$ - globin gene expression in CD34+ HPCs derived from UCB

Two high titer lentiviruses that carry PWPXL-CTDSPL2 and pLVTHM-CTDSPL2 RNAi were obtained. CD34+ HPCs from normal UCB were purified and were infected 


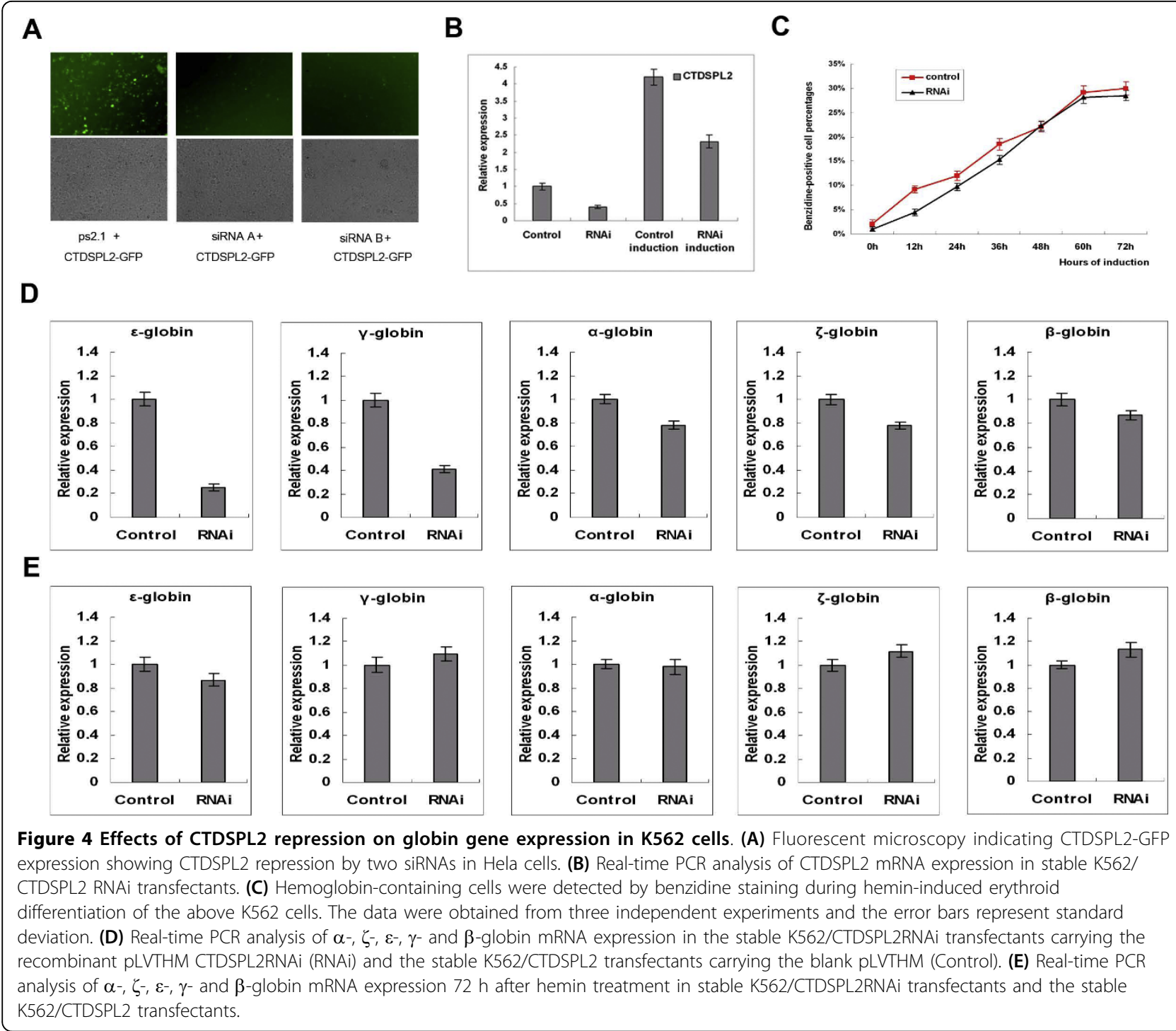

with the two recombinant lentiviruses respectively. The transduction efficiency of the CD34+ cells was about 70-80\% through observing GFP expression. CTDSPL2 mRNA was detected by real-time PCR. CTDSPL2 mRNA levels in CD34+ cells infected by lentiviruses carrying pWPXL-CTDSPL2 were 3.5 times greater than that in control cells (Fig. 5A). CTDSPL2 mRNA levels in CD34+ cells infected by lentiviruses carrying pLVTHMCTDSPL2 RNAi were $55 \%$ of that in control cells (Fig. 5A).

Globin mRNA levels in the lentivirus-infected CD34+ cells were analyzed by real-time PCR before and after Epo-induced erythroid differentiation. There were mainly the $\alpha$ - and $\gamma$-globin gene expression in UCB derived CD34+ cells (Fig. 5B). $\alpha$ - and $\gamma$-globin mRNA levels were 40 times greater after Epo-induced erythroid differentiation (Fig. 5C).
Overexpression of CTDSPL2 gene in CD34+ HPCs increased transcription of all globin genes (Fig. 5D). $\varepsilon$-globin mRNA in CD34+ HPCs overexpressing CTDSPL2 was 2.5 times greater than in control cells. Repression of the CTDSPL2 gene in CD34+ HPCs decreased transcription of the $\varepsilon$-globin gene but had little effect on other globin genes. $\varepsilon$-globin gene expression in CD34+ HPCs with repressed CTDSPL2 was only $22 \%$ of that in control cells.

Transcription of a number of globin genes in the lentivirus-infected CD34+ cells was measured 7 days after induction by Epo (Fig. $5 \mathrm{E}$ ). Increases in $\varepsilon$-globin gene transcription in Epo-induced CD34+ cells were much stronger than in un-induced CD34+ cells. $\varepsilon$-globin gene transcription in CD34+ HPCs overexpressing CTDSPL2 was 5.8 times greater than in control cells. Overexpression of the CTDSPL2 gene also increased $\alpha$ - and $\gamma$-globin 


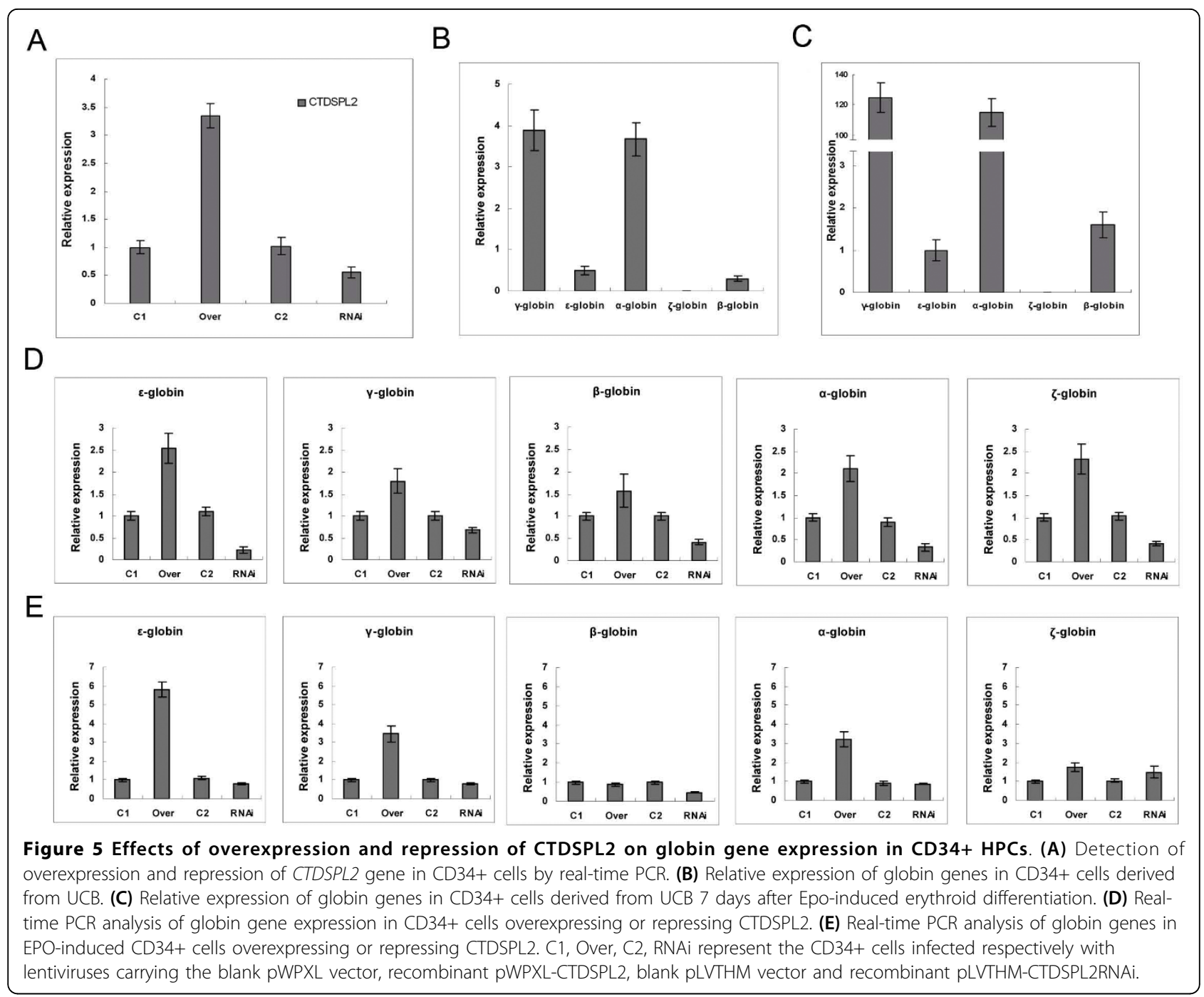

gene transcription in Epo-induced CD34+ cells. Decreases of globin gene transcription in CD34+ cells with repressed CTDSPL2 were no longer observed after erythroid differentiation.

\section{Discussion}

By differential display analysis, we found that the transcription of the CTDSPL2 gene in UCB erythroid cultures was greater than in adult BM erythroid cultures. Meanwhile, $\gamma$-globin gene developmentally expressed mainly in UCB and little in adult BM [15]. Furthermore, we measured transcription levels of CTDSPL2 during hemininduced erythroid differentiation of $\mathrm{K} 562$ cells and Epoinduced erythroid differentiation of CD34+ HPCs and found that its expression increased significantly during erythroid differentiation. $\gamma$-globin gene transcription also increased significantly during hemin-induced erythroid differentiation in K562 cells and Epo-induced erythroid differentiation in CD34+ HPCs $[16,17]$. Based on this evidence, we hypothesized that CTDSPL2 plays a role in $\gamma$-globin gene activation.

CTD phosphatases can dephosphorylate the CTD tail of the largest subnit of RNAPII and play a major role in mRNA processing. Only a few mammalian CTD phosphatases have been identified [12]. CTD small phosphatase like 2 (CTDSPL2) contains a CTD phosphatase catalytic domain (CPDc) and dephosphorylates phophoserine-5 and phosphoserine-2 within GST-CTDo in vitro [14].

The K562 cell line was chosen for this study as it is commonly used to study globin gene regulation $[18,19]$. We prepared five stable K562/pc3.1-CTDSPL2 transfectant pools. Benzidine staining showed that overexpression of the CTDSPL2 gene increased the number of hemoglobin-containing cells during K562 erythroid differentiation. To determine which globin genes are affected, a number of globin genes (including $\alpha_{-}, \zeta_{-}, \varepsilon_{-}^{-}$, $\gamma$ - and $\beta$-globin genes) were analyzed. The results showed 
that overexpression of CTDSPL2 increased the transcription of $\varepsilon$ - and $\gamma$-globin genes in $\mathrm{K} 562$ cells before and after erythroid differentiation, while there was only a small effect on the $\alpha-, \zeta$ - and $\beta$-globin genes. Of course, the random integration into genome and the incomplete simulation of endogenous gene in overexpression study may arise some trustless results. But the use of several stable transfectant pools in this study may partially overcome this disadvantage.

CTDSPL2 may be specifically recruited into the transcriptional initiation complex at the $\varepsilon$ - and $\gamma$-globin gene promoters through interaction with $\varepsilon$ - and $\gamma$-globin specific transcription factors. In order to identify candidate transcription factors, CTDSPL2-interacting proteins will need to be determined. Expression of the erythroid surface marker, CD71, increased to some degree in the stable K562/pc3.1-CTDSPL2 transfectant pools (data not shown). So, it is also possible that CTDSPL2 increased $\varepsilon$ - and $\gamma$-globin gene expression by increasing erythroid differentiation of K562 cells partially.

To determine if CTDSPL2 is necessary for $\varepsilon$ - and $\gamma$-globin gene expression, we examined the effect of CTDSPL2 repression by RNAi on globin gene expression in $\mathrm{K} 562$ cells. Repression of the CTDSPL 2 gene decreased the transcription of the globin genes, especially the $\varepsilon$-globin gene. However, repression of CTDSPL2 did not inhibit the increase of globin gene expression during hemininduced erythroid differentiation. Therefore, CTDSPL2 can increase $\varepsilon$ - and $\gamma$-globin gene expression but it is not indispensable for increases of $\varepsilon$ - and $\gamma$-globin gene expression during erythroid differentiation. There may be other genes that can compensate for CTDSPL2 in the activation of globin gene expression. Alternatively, CTDSPL2 level is decreased but not eliminated in our experiments. Transcription of CTDSPL2 in stable K562/ CTDSPL2 RNAi transfectants still increased during erythroid differentiation. This may explain why repression of CTDSPL2 could not inhibit the increase of globin gene expression during erythroid differentiation.

The effects of CTDSPL2 on globin gene expression in CD34+ hematopoietic progenitor cells were also examined. CD34+ hematopoietic progenitor cells were quiescent and generally non-dividing. Lentiviruses can effectively infect quiescent, non-divisive cells and are widely used in hematopoietic stem cell gene therapy $[20,21]$. We achieved overexpression and repression of the CTDSPL2 gene in CD34+ cells by lentivirus infection. The effects in lentivirus-infected CD34+ cells were consistent with those in transfected K562 cells. CTDSPL2 overexpression significantly increased $\varepsilon$-globin gene expression and also increased $\gamma$-globin gene transcription. The greater effect of CTDSPL2 on $\varepsilon$-globin gene transcription than $\gamma$-globin gene transcription may be partly due to the high baseline level of $\gamma$-globin gene transcription in $\mathrm{K} 562$ cells and UCB-derived CD34+ HPCs. In future studies, the effect of CTDSPL2 on $\gamma$-globin gene transcription will be measured in bone marrow-derived CD34+ HPCs in which there is little $\gamma$-globin gene expression.

The expression of CTDSPL2 increased significantly during erythroid differentiation. This suggested that its expression may be regulated by erythroid differentiation-related factors. The analysis of its promoter and mechanism of its specific expression is necessary. The overexpression of CTDSPL2 can specifically increase epsilon and gamma globin spontaneous expression, but CTDSPL2 does not contain a DNA binding domain. So it is impossible for CTDSPL2 to bind to epsilon and gamma-globin gene promoter directly. And it is possible that it was recruited to epsilon and gamma-globin gene promoter by interacting with some important globin related transcriptional factors such as EKLF, FKLF, NF-E4, etc. So to find the possible CTDSPL2 interacting protein through immunoprecipitation or two hybrid system in mammalian cell is the next step. In addition to identify the existence of CTDSPL2 in epsilon and gamma globin gene promoter complex through chromatin immunoprecipitation is also necessary. On the other hand, it is possible that CTDSPL2 regulate the phosphorylation status of the key factors in globin gene expression. It is reported that SCP1 can dephosphorylate Ser- 2 and Ser -5 of phosphorylated RNA polII CTD in vitro as FCP1 (the first characterized CTD phosphatase) [13]. It is also reported that SCP1-3 can dephosphorylate Smad1 C-terminal tail, thereby attenuating BMP signaling [22]. It also can dephosphorylate the linker regions of Smad1 and Smad2/3 in vitro [23]. So the substrate of CTDSPL2 may be various not limited to the CTD tail of RNA polII.

\section{Conclusions}

In conclusion this study showed that CTDSPL2 increases $\varepsilon$ - and $\gamma$-globin gene expression in $\mathrm{K} 562$ cells and UCB-derived CD34+ HPCs. Reactivation of the $\gamma$-globin gene in the adult has been demonstrated to be significant for treatment of SCD and $\beta$-thalassemia. The reactivation of the $\varepsilon$-globin gene should also have similar effects. Thus our study provides a new candidate target for effective treatment of SCD and $\beta$-thalassemia through activation of $\varepsilon$ - and $\gamma$-globin genes in adults. Further investigation of the mechanism of CTD phosphatase in globin gene regulation may open new ways to regulate gene transcription with CTD phosphatases.

\section{Methods}

\section{Cell culture and induction to erythroid differentiation}

Informed consent was obtained from all donors. Four UCB samples (40 to $50 \mathrm{ml}$ each) from normal full-term deliveries and four BM samples (5 to $10 \mathrm{ml}$ each) from 
healthy adult donors were collected using EDTA as the anti-coagulant. UCB samples were diluted 1:4 with phosphate buffered saline (PBS) containing $2 \mathrm{mM}$ EDTA and $0.5 \%$ bovine serum albumin (BSA, Sigma, St. Louis, MO, USA). To release the cells, BM samples were diluted with 10 volumes of RPMI 1640 (Gibco, Invitrogen, Grand Island, NY, USA) containing 0.02\% collagenase B and $100 \mathrm{U} / \mathrm{ml}$ DNase (Sigma, St. Louis, MO, USA) and incubated at room temperature for $45 \mathrm{~min}$. Mononuclear cells (MNCs) were isolated from the diluted UCB and BM by centrifugation on a gradient of Ficoll-Hypaque (density $1.077 \mathrm{~g} / \mathrm{ml}$, Sigma, St. Louis, MO, USA) [24]. CD34+ HPCs were purified by positive selection using Mini-MACS columns according to the manufacturer's protocol (Milternyi Biotech, Germany). The purity of CD34+ cells was then determined (>90\%).

Cells were cultured as described previously [25]. Briefly, CD34+ HPCs purified from UCB were cultured in Iscove's modified Dulbecco's medium (IMDM, Gibco, Invitrogen, Grand Island, NY, USA) containing 1\% deionized bovine serum albumin (BSA, fraction V, Sigma, St. Louis, MO, USA), 30\% human cord serum (CHS, prepared in-house, heterologous), $1 \times 10^{-5} \mathrm{~mol} / \mathrm{L} 2$-mercaptoethanol (Sigma, St. Louis, MO, USA), $2 \times 10^{-3}$ mol/L L-glutamine (Sigma, St. Louis, MO, USA), antibiotics (Gibco, Invitrogen, Grand Island, NY, US) and cytokines (R\&D System, Minneapolis, MN. USA) including $2 \mathrm{IU} / \mathrm{ml} \mathrm{Epo,} 100 \mathrm{ng} / \mathrm{ml} \mathrm{SCF}$ and $2 \mathrm{ng} / \mathrm{ml} \mathrm{IL-3.}$ CD34+ cells from BM were cultured in the same serum-containing medium except that $30 \%$ CHS was substituted with $30 \%$ human adult AB-type serum (AHS, TBD, Tianjin, P R China). All CD34+ cells were seeded at $1 \times 10^{5}$ cells $/ \mathrm{ml}$ in $6 \mathrm{ml}$ cultures and incubated in a humidified atmosphere at $37^{\circ} \mathrm{C}$ and $5 \% \mathrm{CO}_{2}$ for three weeks.

K562 cells were cultured in DMEM medium (Gibco, Invitrogen, Grand Island, NY, USA) containing $10 \%$ fetal bovine serum and $2 \times 10^{-3} \mathrm{~mol} / \mathrm{L} \mathrm{L}$-glutamine at $37^{\circ} \mathrm{C}$ and $5 \% \mathrm{CO}_{2}$ and were induced to erythroid differentiation with $40 \mu \mathrm{mol} / \mathrm{L}$ hemin [26]. Cells were counted with a hemocytometer and hemoglobin-containing erythroid cells were identified by benzidine staining.

\section{RNA preparation, CDNA synthesis and real-time PCR}

Total RNA was extracted from cell samples using TRIzol $^{\oplus}$ reagent (Invitrogen, Carlsbad, CA, USA) and quantitated by spectrophotometer. The first-strand of cDNA was synthesized using Superscript ${ }^{\mathrm{TM}}$ III reverse transcriptase (Invitrogen, Carlsbad, CA, USA). Gene-specific primers were designed using Primer Express (Applied Biosystems, Foster City, CA) software Version 2.0 (Table 1) [27]. The mRNA level of target genes in cultured erythroid cells was quantified by real-time PCR analysis on an ABI PRISM $^{\odot} 7500$ real-time PCR System (Applied Biosystems,
Table 1 Oligonucleotide primer sets used in quantitative real-time PCR experiments

\begin{tabular}{|c|c|c|}
\hline Gene & Primer Sequence $\left(5^{\prime}-3^{\prime}\right)$ & Product Size (bp) \\
\hline$\gamma$-globin & $\begin{array}{l}\text { GCAGCTTGTCACAGTGCAGTTC } \\
\text { TGGCAAGAAGGTGCTGACTTC }\end{array}$ & 166 \\
\hline$\beta$-globin & $\begin{array}{l}\text { GTCTACCCTTGGACCCAGAGGTTC } \\
\text { TGAGCCAGGCCATCACTAAAG }\end{array}$ & 131 \\
\hline$\varepsilon$-globin & $\begin{array}{l}\text { CAGCTGCAATCACTAGCAAGC } \\
\text { AGACGACAGGTTTCCAAAGC }\end{array}$ & 190 \\
\hline$\alpha$-globin & $\begin{array}{l}\text { GGTCAACTTCAAGCTCCTAAGC } \\
\text { GCTCACAGAAGCCAGGAACTTG }\end{array}$ & 116 \\
\hline$\zeta$-globin & $\begin{array}{l}\text { TGAGCGAGCTGCACGCCTAC } \\
\text { GTACTTCTCGGTCAGGACAGA }\end{array}$ & 173 \\
\hline CTDSPL2 & $\begin{array}{l}\text { TGGAACGTCAGGATCAGATTCTC } \\
\text { GATGGTCTCACTTGAACTGCTTGA }\end{array}$ & 157 \\
\hline GAPDH & $\begin{array}{l}\text { TCAACGACCACTITGTCAAGCTCA } \\
\text { GCTGGTGGTCCAGGGGTCTTACT }\end{array}$ & 119 \\
\hline
\end{tabular}

Foster City, CA) with the SYBR ${ }^{\bullet}$ Premix Ex Taq $^{\mathrm{TM}} \mathrm{kit}$ (Takara, Dalian, P R China). The following PCR cycle parameters were used: $95^{\circ} \mathrm{C}$ for $10 \mathrm{~s}, 40$ cycles at $95^{\circ} \mathrm{C}$ for $5 \mathrm{~s}, 60^{\circ} \mathrm{C}$ for $34 \mathrm{~s}$. Each PCR reaction was performed in triplex tubes with GAPDH as an endogenous control to standardize the amount of sample cDNA. Data were analyzed with sequence detection system (SDS) software (Applied Biosystems, Foster City, CA). The comparative $\mathrm{C}_{\mathrm{T}}$ method was used for quantification of the target genes relative to GAPDH. All real-time PCR analyses were repeated three times.

\section{Differential display reverse transcription PCR}

CD34+ cells derived from UCB and adult BM were collected on day 8 of erythroid culture as our previous results showed that this is when $\gamma$ - to $\beta$-globin switching occurs [25]. Total RNA was prepared as above and differential display reverse transcription-PCR (DDRT-PCR) was performed in combination with 3 anchored primers and 18 arbitrary primers. Briefly, three one-base anchored oligodT primers (A, C, G) were used to synthesize first-strand cDNA that was then amplified with 18 arbitrary primers (long primers) in the presence of $\left[\alpha-{ }^{32} \mathrm{P}\right] \mathrm{dCTP}$. The following PCR cycle parameters were used: $94^{\circ} \mathrm{C}$ for $1 \mathrm{~min}$, $40^{\circ} \mathrm{C}$ for $4 \mathrm{~min}, 72^{\circ} \mathrm{C}$ for $1 \mathrm{~min} ; 35$ cycles at $94^{\circ} \mathrm{C}$ for 1 $\min , 60^{\circ} \mathrm{C}$ for $2 \mathrm{~min}, 72^{\circ} \mathrm{C}$ for $1 \mathrm{~min} ; 72^{\circ} \mathrm{C}$ for $5 \mathrm{~min}$. Each PCR reaction was performed in double tubes to confirm the reproducibility and amplified with GAPDH as an endogenous control to standardize the amount of sample cDNA. PCR products were separated on a $6 \%$ denaturing polyacrylamide gel at $85 \mathrm{~W}$ on the gel board of sequencing (Bio-Rad California, USA) according to the manufacturer's instructions. The gel was analyzed using the Cyclone Storage Phosphor System (Packard, USA) and then exposed for 6 to $12 \mathrm{~h}$ at $-70^{\circ} \mathrm{C}$ on X-film (Kodak, P.R China) after drying at $80^{\circ} \mathrm{C}$ for $120 \mathrm{~min}$ under vacuum (Bio-Rad California, USA). 


\section{Western blot}

Cell lysates containing $50 \mu \mathrm{g}$ protein were loaded on a $12 \%$ SDS-PAGE gel and then were transferred to polyvinylidene difluoride membranes (Amersham) using BioRad's Transblot for $2 \mathrm{~h}$ at $0.2 \mathrm{amp}$ at $4^{\circ} \mathrm{C}$. The membrane was immersed in the blocking buffer (PBS containing 3\% BSA and $0.05 \%$ Tween 20) and blocked overnight. Then the membrane was incubated with the AntiCTDSPL2 (ProTeintech Group, Inc, Chicago, USA) or AntiGAPDH (Abcam, Cambridge, UK) diluted in blocking buffer for $2 \mathrm{~h}$ at room temperature, followed by incubated with the peroxidase-conjugated affinipure goat anit-mouse IgG $(\mathrm{H}+\mathrm{L})$ (Zhongshang Goldenbridge, Beijing, China) diluted in the blocking buffer for $2 \mathrm{~h}$ at room temperature. Then chemiluminescence reaction was performed using ECL Western Blotting Analysis System (Amersham) for $5 \mathrm{~min}$, and then the membranes were exposed to ECL hyper film (Amersham) for $5 \mathrm{~s}-15 \mathrm{~min}$.

\section{Overexpression of CTDSPL2 in K562 cells by lipofectamine transfection}

The cDNA fragment including the complete CTDSPL2coding sequence was subcloned into Hind III-EcoRV of the eukaryotic expression vector pcDNA3.1+ (Invitrogen, Carlsbad, CA, USA). K562 cells were transfected with the recombinant plasmid pc3.1-CTDSPL2 and pc3.1 vector as a control by Lipofectamine 2000 (Invitrogen, Carlsbad, CA, USA). Stable K562 transfectants were selected in the medium containing $500 \mu \mathrm{g} / \mathrm{ml}$ G418 for 2 weeks. Overexpression of CTDSPL2 in $\mathrm{K} 562$ cells was validated by real-time PCR.

\section{Screening for effective RNAi targets of CTDSPL2 gene}

The CTDSPL2 open reading frame (ORF) was analyzed with the Ambion siRNA target finder http://www.ambion. com. Several possible targets for effective RNAi of CTDSPL2 gene were selected. DNA sequences that are siRNAs targets for two sites (326, AAGCTGGTAGTTATGAAATGA; 1057, AAGGTGTATGCAGACAAGTTA) were inserted into the psilencer2.1-U6-neo vector at the BamHI and HindIII sites. The coding sequence of CTDSPL2 gene excluding the stop codon was inserted into the eukaryotic expression vector pEGFP-N1 in frame of EGFP and to produce CTDSPL2-GFP fusion protein expression plasmid. Recombinant RNAi plasmids were then co-transfected with the CTDSPL2-GFP fusion expression plasmid into Hela cells. The green fluorescence was observed to validate CTDSPL2 repression in Hela cells.

\section{Recombinant lentiviruses generation and gene transduction in CD34+ HPCs}

The coding sequence of the CTDSPL2 gene was subcloned into the pWPXL retroviral expression vector at BamHI and MluI sites joining the 5'end of EGFP to obtain the recombinant plasmid pWPXL-CTDSPL2. The effective siRNA sequence was subcloned into the pLVTHM vector at MluI-ClaI site to get recombinant plasmid pLVTHM-CTDSPL2 RNAi. The recombinant plasmids pWPXL-CTDSPL2 or pLVTHM-CTDSPL2 RNAi were co-transfected with packaging plasmid (pSPAX2) and envelope plasmid (pMD.2G) into 293T cells by calcium phosphate. The efficiency of transfection was confirmed by green fluorescence under fluorescence microscopy $48 \mathrm{~h}$ after transfection. The medium was collected by centrifugation $(3000 \mathrm{rpm}, 5 \mathrm{~min}$, room temperature) $72 \mathrm{~h}$ after transfection and then filtered $(0.45 \mu \mathrm{m})$. The viruses were concentrated by centrifugation $\left(26000 \mathrm{rpm}, 2 \mathrm{~h}, 4^{\circ} \mathrm{C}\right)$. The supernatant was discarded and the pellet containing the viruses was resuspended in serum-free medium. The virus concentration was determined by infecting $293 \mathrm{~T}$ cells followed by FACS fluorescence analysis.

For gene transduction into CD34+ HPCs, $2 \times 10^{6}$ viral particles were preloaded onto a RetroNectin-coated plate (Takara, Dalian, China) and incubated at $37^{\circ} \mathrm{C}$ for $5 \mathrm{~h}$. Just prior to infection, the viral supernatant was discarded and the plate was washed with PBS [28]. Approximately $1 \times 10^{5} \mathrm{CD} 34+$ cells were then added to the preloaded viral plate with growth medium, and the plate was incubated at $37^{\circ} \mathrm{C}$. Seventy-two hours after lentiviruses infection, infected CD34+ cells were induced to erythroid differentiation by Epo for a week.

\section{RNase protective assay}

Human globin mRNAs were analyzed by quantitative RNase protection assays. Four plasmids containing the pT7 promoter and a fragment of each of the genes were used as probe templates. pT7 $\varepsilon$, pT7 $\gamma$, pT7 $\alpha$, pT7 $\beta$-actin were acquired by cloning EcoRI-KpnI fragments of these genes downstream from the pT7 promoter in pcDNA3.1 + , linearized with $\mathrm{XbaI}$, giving a protected fragment derived from exons of their mRNAs of 231 nucleotides, 169 nucleotides, 149 nucleotides, 121 nucleotides respectively. pT7 $\beta$ came originally from Dr. Li at the University of Washington [17]. RNA probes, labeled with $\alpha$-p32 UTP, were obtained by in vitro transcription of the plasmids with T7 polymerase and purified according to the manufacturer's instructions (Promega, Madison, WI, USA). Total RNA ( $4 \mu \mathrm{g}$ ) was hybridized with $3 \times 10^{5} \mathrm{cpm}$ of each probe at $90^{\circ} \mathrm{C}$ for $2 \mathrm{~min}$ and then incubated for $12-16 \mathrm{~h}$ at $56^{\circ} \mathrm{C}$. RNA samples were then digested with RNase A and T1 for $45 \mathrm{~min}$ at $30^{\circ} \mathrm{C}$ and incubated with Proteinase $\mathrm{K}$ for $15 \mathrm{~min}$ at $37^{\circ} \mathrm{C}$, using the ribonuclease protection assay kit (BD Bioscience, Franklin Lakes, USA). Protected fragments were purified by extraction with chloroform and precipitation with ethanol. Then the samples were denatured at $90^{\circ} \mathrm{C}$ for 3 min before separation on a $4.75 \%$ acrylamide/8 M 
urea gel at $85 \mathrm{~W}$ on the gel sequencing board (Bio-Rad, California, USA). Gels were analyzed with the Cyclone Storage Phosphor System (Packard, USA) and then exposed for 6 to $12 \mathrm{~h}$ at $-70^{\circ} \mathrm{C}$ on X-film (Kodak, P.R China).

\section{Statistical analysis}

Statistical analysis was performed using Student's paired $t$ test, $p$ values less than 0.05 were considered to be significant. All data were expressed as mean \pm S.E, and statistical analyses were performed by SPSS version 10.0.

\section{Acknowledgements}

This work is supported by the National Nature Science Foundation of China (No.30393110), National High Technology Research and Development Program of China (No.2002AA223071), National Basic Research Program of China (No. 2006CB504100 and 2010CB530406) and Special Foundation for Doctoral Degree Expediency (20060023031). We also thank Dr. Li at the University of Washington for the pT7 $\beta$ plasmid.

\section{Authors' contributions}

YNM made substantial contributions to design, acquisition of data, analysis of data and drafted the manuscript. $X Z$ participated in the design of the study and carried out DDRT-PCR. HCY performed the Western blot analysis. JWZ conceived of the study, designed and directed the research, helped to analysis data and to draft the manuscript. All authors read and approved the final manuscript.

Received: 31 December 2009 Accepted: 9 October 2010

Published: 9 October 2010

\section{References}

1. Harju S, McQueen KJ, Peterson KR: Chromatin structure and control of beta-like globin gene switching. Exp Biol Med 2002, 227:683-700.

2. Stamatoyannopoulos G, Grosveld F: Hemoglobin switching. In The Molecular Basis of Blood Diseases. Edited by: Stamatoyannopoulos G, Majerus P, Perlmutter R, Varmus H. Philadelphia; 3 2001:135-182.

3. Rodgers GP, Rachmilewitz EA: Novel treatment options in the severe beta-globin disorders. Br J Haematol 1995, 91:263-268.

4. Ley TJ, DeSimone J, Noguchi CT, Turner PH, Schechter AN, Heller P, Nienhuis AW: 5-Azacytidine increases gamma-globin synthesis and reduces the proportion of dense cells in patients with sickle cell anemia. Blood 1983, 62:370-380

5. Charache S, Dover GJ, Moore RD, Eckert S, Ballas SK, Koshy M, Milner PF, Orringer EP, Phillips G Jr, Platt OS: Hydroxyurea: effects on hemoglobin F production in patients with sickle cell anemia. Blood 1992, 79:2555-2565.

6. Rodgers GP, Dover GJ, Noguchi CT, Schechter AN, Nienhuis AW: Hematologic responses of patients with sickle cell disease to treatment with hydroxyurea. N Engl J Med 1990, 322:1037-1045.

7. Perrine SP, Ginder GD, Faller DV, Dover GH, Ikuta T, Witkowska HE, Cai SP, Vichinsky EP, Olivieri NF: A short term trial of butyrate to stimulate fetalglobin-gene expression in the beta-globin disorders. N Engl J Med 1993 328:81-86

8. Atweh GF, Sutton M, Nassif I, Boosalis V, Dover GJ, Wallenstein S, Wright E, McMahon L, Stamatoyannopoulos G, Faller DV, Perrine SP: Sustained induction of fetal hemoglobin by pulse butyrate therapy in sickle cell disease. Blood 1999, 93:1790-1797.

9. Chaine B, Neonato MG, Girot R, Aractingi S: Cutaneous adverse reactions to hydroxyurea in patients with sickle cell disease. Arch Dermatol 2001, 137:467-470.

10. Hanft VN, Fruchtman SR, Pickens CV, Rosse WF, Howard TA, Ware RE: Acquired DNA mutations associated with in vivo hydroxyurea exposure. Blood 2000, 95:3589-3593.

11. Licciardo P, Amente S, Ruggiero L, Monti M, Pucci P, Lania L, Majello B: The FCP1 phosphatase interacts with RNA polymerase II and with MEP50 a component of the methylosome complex involved in the assembly of snRNP. Nucleic Acids Res 2003, 31:999-1005.

12. Chambers RS, Dahmus ME: Purification and characterization of a phosphatase from HeLa cells which dephosphorylates the $C$ terminal domain of RNA polymerase II. J Biol Chem 1994, 269:26243-26248.

13. Yeo M, Lin PS, Dahmus ME, Gill GN: A novel RNA polymerase II C-terminal domain phosphatase that preferentially dephosphorylates serine 5 . J Biol Chem 2003, 278:26078-26085.

14. Qian H, Ji C, Zhao S, Chen J, Jiang M, Zhang Y, Yan M, Zheng D, Sun Y, Xie Y, Mao Y: Expression and characterization of HSPC129, a RNA polymerase II C-terminal domain phosphatase. Mol Cell Biochem 2007, 303:183-188.

15. Baron $\mathrm{MH}$ : Developmental regulation of the vertebrate globin multigene family. Gene Expr 1996, 6:129.

16. Sasaki D, Kosunago S, Mikami T, Matsumoto T, Suzuki M: Growth-inhibition by hemin in $\mathrm{K} 562$ human leukemic cells is related to hemoglobinproducing activity. Biol Pharm Bull 1994, 17:586-590.

17. Zhang $X$, Luo YM, Ma YN, Zhang JW: In vitro maturation of erythroid progenitors from human umbilical cord blood and patterns of globin gene expression: serum from different developmental stage plays important roles in liquid culture. Biochem Biophys Res Commun 2005, 336:42-48.

18. Rutherford TR, Clegg JB, Weatherall DJ: K562 human leukaemic cells synthesise embryonic haemoglobin in response to haemin. Nature 1979, 280:164-165.

19. Bianchi N, Ongaro F, Chiarabelli C, Gualandi L, Mischiati C, Bergamini P, Gambari R: Induction of erythroid differentiation of human K562 cells by cisplatin analogs. Biochem Pharmacol 2000, 60:31-40.

20. Logan AC, Lutzko C, Kohn DB: Advances in lentiviral vector design for gene-modification of hematopoietic stem cells. Curr Opin Biotechnol 2002, 13:429-436.

21. Sirven A, Pflumio F, Zenbou V, Titeux M, Vainchenker W, Coulombel L, Dubart-Kupperschmitt A, Charneau P. The human immunodeficiency virus type-1 central DNA flaps is a crucial determinant for lentiviral vector nuclear import and gene transduction of human hematopoietic stem cells. Blood 2000, 96:4103-4110.

22. Knockaert M, Sapkota G, Alarcón C, Massagué J, Brivanlou AH: Unique players in the BMP pathway: small C-terminal domain phosphatases dephosphorylate Smad1 to attenuate BMP signaling. Proc Natl Acad Sci 2006, 103:11940-11945.

23. Sapkota G, Knockaert M, Alarcón C, Montalvo E, Brivanlou AH, Massagué J: Dephosphorylation of the linker regions of Smad1 and Smad2/3 by small C-terminal domain phosphatases has distinct outcomes for bone morphogenetic protein and transforming growth factor-beta pathways J Biol Chem 2006, 281:40412-40419.

24. Böyum A: Separation of leukocytes from blood and bone marrow. Scand J Clin Lab Invest Suppl 1968, 97:7-12.

25. Ma YN, Zhang X, Zhang JW, Zhang XH, Wang RX: Screening for transacting factors and other factors involved in the activating or silencing of the gamma-globin gene during human ontogeny. Biochem Cell Biol 2007, 85:347-357.

26. Liu LR, Du ZW, Zhao HL, Liu XL, Huang XD, Shen J, Ju LM, Fang FD, Zhang JW: $T$ to $C$ substitution at -175 or -173 of the gamma-globin promoter affects GATA-1 and Oct-1 binding in vitro differently but can independently reproduce the hereditary persistence of fetal hemoglobin phenotype in transgenic mice. J Biol Chem 2005, 280:7452-7459.

27. Kociok N, Hueber A, Esser P, Schraermeyer U, Thumann G, Luther $\Pi$, Jordan J, Welsandt G, Kirchhof B: Vitreous Treatment of Cultured Human RPE Cells Results in Differential Expression of 10 New Genes. Invest ophthalmol Vis Sci 2002, 43:2474-2480.

28. Tang DC, Zhu J, Liu W, Chin K, Sun J, Chen L, Hanover JA, Rodgers GP: The hydroxyurea-induced small GTP-binding protein SAR modulates gammaglobin gene expression in human erythroid cells. Blood 2005, 106:3256-3263.

doi:10.1186/1471-2121-11-75

Cite this article as: Ma et al:: CTD small phosphatase like 2 (CTDSPL2) can increase $\varepsilon \varepsilon$ - and $\gamma /$-globin gene expression in K562 cells and CD34+ cells derived from umbilical cord blood. BMC Cell Biology 2010 11:75. 